\title{
IN MEMORIAM \\ Miguel CRUZ HERNÁNDEZ
}

\author{
(15.I.1920-25.V.2020) \\ RAFAEL RAMÓN GUERRERO \\ COMPLUTENSE UNIVERSITY OF MADRID
}

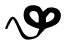

Las difíciles y pavorosas circunstancias por las que España y otros países del mundo atravesaban en el mes de marzo hicieron que pasase casi inadvertida la muerte de uno de nuestros más grandes estudiosos de la filosofía en el mundo islámico, D. Miguel Cruz Hernández. Fue el día 25 de marzo, dos meses y diez días después de haber cumplido los cien años, pues había nacido en Málaga el 15 de enero de 1920. Bien pronto sus padres maestros se trasladaron a Granada, donde realizó sus estudios universitarios y donde descubrió la filosofía y los estudios árabes. La suya ha sido una vida centenaria dedicada toda ella a la lectura y al estudio. Digo a la lectura, porque como confesaba el propio D. Miguel, desde muy niño se le despertó « el vicio de la lectura cuando iba a cumplir los seis años ». Desde entonces y hasta prácticamente el día de su muerte, D. Miguel vivió en los libros y para los libros, pero también para la actividad social y política, como lo muestra su participación en diversas tareas dedicadas por una parte a la sociedad desde muy temprano en su vida (miembro de la Federación Universitaria Escolar y miembro de las Juventudes Socialistas Unificadas), habiendo desempeñado notables cargos políticos (Alcalde de Salamanca, 1959-1962, Gobernador Civil de Albacete, 1962-1968), y, por otra, a la universidad, en la que desempeñó su labor docente desde los veinticuatro años de edad, cuando en 1944 comenzó a impartir clases de filosofía en la Facultad de Filosofía y Letras de la Universidad de Granada, en la que se había licenciado en filología semítica en junio de 1943.

La publicación Anthropos. Revista de documentación científica de la cultura, (86/87) 1988, estuvo dedicada expresamente a M. Cruz Hernández. Pensamiento Islámico. Investigación de su tradición y actualidad, donde, además de artículos publicados por algunos de sus alumnos glosando sus virtudes y sus aportaciones, D. Miguel nos
\end{abstract}


ofrecía una autobiografía, « Autopercepción intelectual de un proceso histórico. Itinerarium vitae in philosophiam », en la que pasa revista a su itinerario intelectual, comenzando con las siguientes palabras: « Mi gusto por la filosofía nació en los duros años de la Guerra Civil (1936-1939) ». Un gusto que se inició con la lectura de las obras de Kant Lo bello y lo sublime y La paz perpetua. Desde entonces, a Kant lo "puse en el altar de mi particular filosofía». Pero fueron sus maestros en la Facultad de Filosofía y Letras de Granada, José Corts Grau y Enrique Gómez Arboleya, quienes definitivamente le orientaron hacia el saber filosófico, trabajando en el pensamiento de Franz Brentano, a quien consagró lo que debería haber sido su tesis doctoral. Pero rechazada por la Universidad de Madrid, única que concedía en aquellos momentos el título de doctor, con la peregrina razón de que su licenciatura era en filología semítica, hubo de proponer un nuevo tema de investigación para la tesis, recayendo su estudio en el filósofo musulmán Avicena y en su metafísica, porque con él aunaba su especialización en lenguas semíticas y su interés por la filosofía. El estudio de Brentano le había llevado a una inicial publicación Contribución al estudio de la intencionalidad en la filosofía árabe, aparecido en el Boletín de la Universidad de Granada, en el año 1945. Al año siguiente, en este mismo Boletín, daba a la luz un artículo sobre la filosofía de Martin Heidegger, fruto de sus lecturas del filósofo alemán. En diciembre de 1946, por fin, leía su tesis doctoral en la Universidad madrileña, a la que en 1947 se le concedió el premio extraordinario. La tesis, con el título La Metafísica de Avicena, fue publicada por la Universidad de Granada en 1949 y los textos avicenianos que había traducido en ella aparecieron, anotados, bajo el epígrafe Avicena "Sobre Metafísica ». Antología, en Madrid, Ed. Revista de Occidente, 1950.

Hay que reseñar ahora que, como él mismo narra, su interés por el pensamiento islámico nació cuando su profesora de árabe, $\mathrm{D}^{\mathrm{a}}$ Joaquina Eguaras Ibáñez, la tan admirada y querida profesora que nos enseñó las letras árabes a muchos de nosotros en la Escuela de Estudios Árabes y en su despacho del Museo Arqueológico de Granada, del que era directora, le orientó hacia una beca vacante en la Escuela de Estudios Árabes, creada a instancias de D. Emilio García Gómez, catedrático de árabe en la Universidad granadina desde el año 1930.

Tras diversos viajes y estancias en el extranjero, D. Miguel obtuvo la cátedra de Filosofía en la Universidad de Salamanca en 1950, ciudad en la que « pronto fui un salmantino más » y en donde durante más de veinticinco años desempeñó su «labor docente y de investigación en las Facultades de Filosofía y Letras y de Medicina y en la Universidad Pontifica », enseñando filosofía, historia de la filosofía y psicología, así como cursos sobre pensamiento islámico. Recorrer la vida de D. Miguel es tener que diversificarse necesariamente en múltiples direcciones: desde el arabismo y la islamología a la filosofía, a la medicina y a la psicología, sin olvidar su paso por el Instituto Hispano-Árabe de Cultura, del que fue nombrado subdirector en 1954, siendo director D. Emilio García Gómez. En 
1976 se trasladó a la Universidad Autónoma de Madrid, donde continuó su docencia en el Departamento de Estudios Árabes e Islámicos, impartiendo la disciplina de Pensamiento Islámico, incluso después de jubilarse, ya como Catedrático Emérito.

A lo largo de su vida Cruz Hernández ha investigado y publicado sobre aquellas materias que tuvo que impartir. Así, además de numerosos artículos sobre Suárez, Brentano, Heiddeger, Unamuno, García Morente, Kant y Newton, San Anselmo, etc., publicó también como libros unas Lecciones de Psicología en 1960, reimpresas varias veces, y El pensamiento de Ramon Llull, en 1977, por el que entró a formar parte como Magister de la Maioricensis Schola Lullistica establecida en Palma de Mallorca.

Pero, como ya he dicho, uno de los más fructíferos campos en los que ha trabajado y en los que nos ha iluminado con su saber ha sido el de la filosofía en el Islam: desde su primer trabajo hasta sus últimos estudios, la vida de Cruz Hernández ha sido la de una consagración continua a la historia de la filosofía árabe, dando a conocer multitud de aspectos y facetas de esta filosofía, abarcando prácticamente la totalidad de este campo de trabajo y de estudio. Ya he señalado sus estudios sobre la metafísica de Avicena. A este autor le consagró diversos trabajos a lo largo de los años, incluso con notables traducciones de sus textos como su versión de la Qasîda fî-l-nafs (Qasîda sobre el alma) (1951) o los Tres escritos esotéricos (1998), donde vierte al español la Risâla de Hayy b. Yaqzân, la Risâla del pájaro, de nuevo la Qasîda del alma, y dos Apéndices: un resumen de la Qissa de la Risâla de Salâmân y Absâl, según el texto de al-Tûsî y dos capítulos de la segunda parte del Kitâb al-Ishârat wa-l-Tanbihât (Libro de las indicaciones y advertencias).

$\mathrm{Su}$ obra más importante, y aquella por la que debe ser considerado un verdadero maestro de quienes se dedican a la historia de la filosofía en el mundo islámico, está formada por las diversas Historias consagradas a esta filosofía. Primero, su Historia de la Filosofía Española. Filosofía Hispano-musulmana, que fue premio Bonilla San Martín y que apareció, en dos volúmenes, en 1957. Después, su obra La filosofía árabe, publicada en la Editorial Revista de Occidente en 1963. Dieciocho años después aparecía su gran Historia del pensamiento en el mundo islámico, fruto de su madurez y resultado de una larga meditación sobre este pensamiento, de la que hay traducción italiana y francesa, revisada y publicada de nuevo en la década de los noventa. En fin, su Historia del pensamiento en alAndalus, publicada en Granada en 1985 para la Biblioteca de cultura andaluza, en la que adapta para un público más amplio los contenidos principales de la filosofía andalusí expuestos en su obra anterior. Son obras de conjunto que ningún otro arabista que haya estudiado la filosofía en el Islam se ha atrevido a hacer. No son meras recopilaciones de lo investigado por otros, sino que su autor se ha servido de las fuentes directamente, ofreciendo el fruto de sus propias investigaciones. Realiza en ellas una ambientación histórica de los autores 
estudiados, describiendo a la par la propia cultura musulmana de la época en que ellos vivieron. Muestra una gran competencia en el conocimiento de los distintos aspectos que configuran esa cultura: teológico, jurídico, místico, etc. Para situar en su preciso lugar el movimiento de la Falsafa, estudia los orígenes del pensamiento islámico y las distintas corrientes aparecidas a lo largo de su historia. Destaca la influencia ejercida por la filosofía griegas en especial el neoplatonismo y el aristotelismo, y sitúa en su contexto real las grandes manifestaciones de la Falsafa oriental: la obra de al-Kindî, el pensamiento de alFârâbî, la gran sistematización de Avicena y la reacción teológica de Algazel. Y, en fin, su tratamiento de la filosofía andalusí es el más completo de cuantas Historias de la Filosofía en el Islam se han escrito hasta el día de hoy. Recoge las diversas tendencias de pensamiento del Islam andalusí; estudia en su marco histórico las características de los grandes nombres de la filosofía en al-Andalus, desde Ibn Masarra hasta Ibn al-Sîd de Badajoz y Abû Salt de Denia, pasando por Ibn Hazm de Córdoba. Dedica notables capítulos a Avempace y a Ibn Tufayl, reconociendo que fueron ellos los que dieron la impronta definitiva a la filosofía andalusí. De Averroes analiza todos los aspectos de su doctrina y su significación histórica. Aun cuando reconoce que con Averroes podía terminar cumplidamente la historia de la filosofía en el Islam, considera también algunos otros desarrollos del pensamiento islámico con autores como Ibn 'Arabî de Murcia o Ibn al-Jatîb, el visir granadino. También estudia la evolución y el proceso histórico de las corrientes esotéricas en Oriente, la gnosofía shi î, la meditación histórica y política de Ibn Jaldûn y lo completa con una amplia visión del pensamiento islámico hasta nuestros días. También hay que destacar en esta obra el tratamiento que D. Miguel ofrece del pensamiento judío, en especial del sefardí y de la síntesis teológica-filosófica de Maimónides, autor al que ha prestado atención en otras publicaciones y Congresos, precisamente porque estos filósofos judíos desarrollaron su quehacer filosófico dentro del mundo islámico y tomando como fuentes, además de sus libros sagrados, la tarea realizada por la filosofía árabe.

Otra línea de investigación y estudio es el que quizá fuera su proyecto más querido, la filosofía y el pensamiento de Averroes, el filósofo cordobés del que hasta hoy no existe un estudio tan completo como el que le tributó en 1986, publicado en Córdoba y titulado Abû l-Walîd ibn Rushd (Averroes). Vida, obra, pensamiento, influencia, reeditado en 1997. Recoge en él, con la minuciosidad propia de un gran científico, todas las novedades y aportaciones con que Averroes contribuyó a engrandecer el pensamiento de Aristóteles, desarrollándolo en la línea que él creía la más verdadera. Pero D. Miguel no se limita sólo al estudio de su filosofía, sino que se ocupa también del Averroes médico y del Averroes jurista. Aparte de sus numerosos trabajos sobre Averroes y sobre la recepción del averroísmo por los latinos - única continuación que tuvo la filosofía del cordobés -, también le debemos la versión castellana de la traducción 
hebrea, perdido el texto árabe original, de la Exposición a la República, que apareció en 1986 y de la que ya circulan varias ediciones.

D. Miguel fue también miembro de la Societé International pour l'Étude de la Philosophie Médiévale, Sociedad fundada en Lovaina en 1958 que nació con la finalidad de promover el estudio del pensamiento filosófico en la Edad Media y la colaboración entre las instituciones y los investigadores que se ocupan de este pensamiento. Habiendo la Sociedad encargado a España que organizara el V Congreso Internacional, D. Miguel fue nombrado Presidente del Congreso y, junto con los Profesores Salvador Gómez Nogales y José Antonio García-Junceda, emprendió la enorme tarea de preparar toda la impedimenta necesaria para la celebración de este Congreso que, con el título Encuentro de culturas en la filosofía medieval, tuvo lugar en Madrid, Córdoba y Granada, entre los días 5 al 12 de septiembre de 1972. Más tarde, y de nuevo gracias a las gestiones de D. Miguel, a la sazón Director General de Cultura Popular y Presidente del Instituto Nacional del Libro Español (1974-1977), se pudieron publicar las Actas de Congreso en dos volúmenes (Madrid, Editora Nacional, 1979).

Muchas otras actividades se podrían señalar en el haber de D. Miguel Cruz Hernández, desde su ocupación universitaria hasta su participación en Congresos y reuniones científicas y académicas nacionales e internacionales, además de su pertenencia a otras sociedades u organismos científicos. Maestro extraordinario de quien hemos aprendido mucho de lo que sabemos, hombre entregado a su quehacer intelectual con una profunda dedicación y amor, persona modesta y sencilla, afable y amena, sabedor de multitud de anécdotas de la historia de España; quienes le hemos tratado y viajado con él, lo recordaremos siempre. Que descanse en paz y que podamos reunirnos con él allá donde esté. 